\title{
When dreams die: parental experience after child death
}

\author{
Research Article
}

\section{Ferdos Pelarak ${ }^{1}$, Shilan Azizi ${ }^{2}$, Elham Merdasi ${ }^{3}$, Ehsan Bandani Tarashoki ${ }^{4}$, Yaghoob Madmoli $^{5}$, Narges Sadeghi ${ }^{6 *}$}

1. Instructor, Department of Nursing and midwifery, Dezful Branch, Islamic Azad University, Dezful, Iran

2. Instructor, Department of Nursing, Bandar Abbas Branch, Islamic Azad University, Bandar Abbas, Iran

3. MSc Student of Nursing, Ahvaz Jundishapur University of Medical Sciences, Ahvaz, Iran

4. Nursing Student, Student Research Committee, Dezful University of Medical Sciences, Dezful, Iran

5. Clinical Nursing Instructor, Gerash University of Medical Sciences, Gerash, Iran

6. Ph.D in Nursing, Department of Nursing, Khorasgan (Isfahan) Branch, Islamic Azad University, Isfahan, Iran

\begin{abstract}
Introduction: Death of a child is considered as one of the greatest devastating failures that makes the continuation of life difficult for the parents. With child's death, parents lose a part of themselves and a part of their future dreams, and their loss is extremely vast and extensive. Hence, the present study has been conducted for the purpose of describing the experiences of parents who have lost a child. Materials and Methods: This study used a qualitative approach through a phenomenological method. Sampling was based on the objective of the research and the method of interview was unstructured and conducted until the full data saturation. Information was gathered through interview with 23 fathers or mothers who had lost their child. Colaizzi's method was used for data analysis. Results: Conducted interviews were analyzed. From the total 371 concept codes, 22 sub concepts along with 7 main concepts were identified. Main concepts include moving forward, mourn, desperation, need for support, consolation, abandoned, and mental impasse. Conclusion: Results of the current study show that the death of a child makes the continuation of life difficult and causes the creation of deep crises for parents; the results of these crises will be the creation of destructive influential reactions in their lives. Real understanding of mental condition of parents at the time of the loss child and then, a necessary step in improving the health of the parents.
\end{abstract}

Keywords: Death, Experience, Children, Parent, Bereavement .

\section{Introduction:}

The loss of a child is one of the most difficult life experiences (1). Bearing this loss is very difficult for parents as they are in a permanent connection with their child. Parents imagine their future expectations and hopes for their children, and what they can provide them with over time, even before they are born (2). The loss of a child is among the most traumatic and devastating events facing an individual or a family (3). It is a tragic and terrifying experience for parents (4), and generally associated with serious psychological reactions . Therefore, several studies have been globally conducted in different fields (e.g. psychology, sociology, epidemiology, medicine, and other social sciences) on the effect of the loss of a child on the health of parents (5). The loss of a child is a shocking and unforgettable event with long-term effects on the life of parents $(6,7)$. According to Thompson et al., the loss of a child is a painful and difficult event with an intense sorrow and grief, which may be experienced by any adult. Accepting the loss of a child by parents is a major crisis that can change their life (8). It is a catastrophe causing damage to the family and resulting in familial confusion (9). The loss of a child has negative impacts on adaptability and physical health, and can

*Corresponding Author:

Narges Sadeghi,

Department of Nursing,

Khorasgan (Isfahan) Branch,

Islamic Azad University, Isfahan, Iran.

Email:n45.sadeghi@yahoo.com be associated with deep social consequences. Qualitative data shows that families experience significant changes after losing a child. Sorrow and grief influences the affected individuals by causing sleep disorder, loss of appetite, restlessness, exhaustion, mental occupation, anxiety, fear of losing interest and motivation, irritability, constant crying, and physical symptoms (10). Parents who lose a child see themselves captivated between death and life. A mother says, "... I died with the death of my child." (11). When a child dies, which is a devastating loss, parents lose a part of their existence and future aspirations. When parents die, people lose their past, but when a child dies, parents lose their future. This difference increases the intensity of failure by a person who loses a child (12). The loss of a child results in great pain and suffering. Pain and suffering are human experiences. Some mothers described such pain and suffering as if their hearts were torn apart(13). According to Glimmer (2008) et al., reduced quality of life, physical diseases, death, etc. are among risk factors following the loss of a child. People's experience and beliefs have significant effects on all dimensions of their lives. Identification of these experiences is possible only by being in the actual context and conducting qualitative studies. Collecting information about parents' experience of losing a child may contribute to a greater attention to such mothers and families, and better provision of them with mental support. Variables affecting this experience (social support, religious ceremonies, and mental symptoms, such as grief and shame) should be identified. These supports should be initiated in hospitals and continue within the family, social organizations, and spiritual institutions. Such experiences and descriptions of them can be used to take a step towards proper 
planning concerning how to provide this group of families with advice and support. Actual understanding of psychological and mental conditions of parents when losing a child and after that is an essential step towards their health improvement. This study was conducted with the aim of exploring the experiences of parents whose loss child.

\section{Materials and Methods}

This was a qualitative phenomenological study in which the nature of human experience about different phenomena is investigated by the researcher $(14,15)$. Regarding the qualitative nature of the research subject, "parents' experience of losing a child," the research methodology was proportionally phenomenological. Purposive sampling was used. It should be noted that in qualitative studies, unlike the saturation stage, the sample size is not very important $(14,16)$. In this study, in-depth and non-structural interview, along with observation was employed. The interviews were tape-recorded and the researcher tried to use open questions and pay attention to nonverbal responses of participants in confirming and showing their interest, aiming to gain an in-depth understanding. The researcher initiated the interview with a general question, "Talk about your experience when you heard of the death of your child." Next questions were asked based on the responses. This study was performed in summer 2013. In the present study, the researcher sent ten thousand text messages to area code 0916 belonging to Khuzestan Province in Iran, to call for participation. Inclusion criteria: Parents who were interested and willing to participate in the research and expression of their experiences were parents who were alert and capable of expressing their experiences. Exit criteria: Parents who were discontinued from collaborating in research, parents who were unable to continue to work for their physical and mental conditions. After the subjects were enrolled, a 30-minute session was held a day prior to the interview to describe research objectives, obtain written and oral consent, and decide the time and location of interviews based on the subjects' convenience. In this study, 23 interviews were carried out, among which 19 interviews were held in the subjects' place of living, and four interviews were done at the interviewer's place due to the subjects' demand. The length of interviews varied between one to four hours, according to the willingness of participants. Parents were interviewed separately, except one couple who asked to be interviewed at the same time. Before the initiation of the interviews, the subjects were asked again to give their consent for recording their interview. They were also assured about the confidentiality of their information and voice. All interviews were carried out by the researcher. Data analysis was done based on the nine-stage Colaizzi's method as follows. All interviews were recorded after obtaining the interviewees' consent. Then, they were transcribed and analyzed until the interview codes (concepts) were obtained. This process was repeated in the next interviews and continued until data was saturated. Field notes were also taken for further documentation of observations. These notes were taken from observations and oral statements seen and heard by the researcher, as well as the researcher's own thoughts and perceptions. They then were used as a part of analysis. In this process, non-verbal gestures, such as crying and tone, were taken into consideration and recorded at the end of the interviews when the interviewee left the place. Before the initiation of a qualitative study, the researcher has to determine his/her own thoughts and perceptions about the subject. The aim is that the researcher gains an understanding of his/her beliefs about the subject to avoid probable subjectivity which may occur during data collection and analysis. The analysis of ideas helps researchers to see and hear what is real to participants rather than what they think is real (17). In the present study, the researcher wrote down all of her thoughts and feelings. She also wrote down all new thoughts and feelings developed during the study in her diary. The researcher performed the exclusion before the initiation of the study and continued it during the study. Trustworthiness of the findings was examined in terms of credibility, dependability, Conformability and transferability. Credibility: Prolonged engagement with research participants was considered. The transcript interviews, derived codes and some subgroups were discussed with participants and two qualitative research experts, and their opinions were considered. Also, a combination of data collecting methods was used (interviews and field notes). Dependability: All accomplished activities were recorded precisely from the first step of the study. Conformability: Various participants were selected among parents who they lost their children through an accident or illness. This study was extracted from a master's thesis in nursing in Islamic Azad University of Nursing and Midwifery in Khorasgan, registered under the Code No. 2381040390201019. It was also approved under the Ethical Code No. 492028.

\section{Results}

Findings of this study, concerning the experience of a parent who has lost a child, were extracted through interview. To achieve research objectives, 23 parents with the experience of child loss were interviewed. The age range of participants was 28-60 years with the mean of 42 years. Among the participants, there were 13 mothers and 10 fathers. In this study, parents of 16 dead children were interviewed. The age of the children, including 10 boys and 6 girls, ranged between 1 and 19 years. There were seven couples among 23 interviewees, and the remaining subjects included mothers or fathers alone. The causes of death were divided into two categories: unintentional events (nine children) and disease (seven children). Seven families had only one child and the remaining families had at least two children. Among 371 conceptual codes, 22 subconcepts and seven key concepts were identified. The key concepts included moving forward, mourning, frustration, need for support, consolidation, abandoned, and psychological impasse.

\section{Moving Forward}

Participants in the study looked forward to the future of their life and hoped for a miracle in their lives that sparked them.

"...I see people are in a rush for worthless things in the world. since my son died, I have become a stronger believer. Without these beliefs, I could not stand. I cannot see in myself to oppose God. It was a difficult divine test, but I ask God what happened if my son was alive. I always wait for his return. "(Participant\#12, age 34, mother)

\section{Mourning}

Most parents expressed a child's loss as a multidimensional and immature experiment that caused severe distress, anxiety, and stress, and constant worries.

"... when I remember the funeral day, my body becomes cold, my heart goes weak, I feel bad and dizzy, I don't know what is happening to me, nothing can make me calm, and I fear to look at his picture. When I remember that day, I start 
crying unintentionally, I want to tear apart my collar and scream, but I control myself. Who knows what I am saying?" (Participant\#2, age 38, father)

Need for Support: From the study that participants referred to in this study, the basic concept of "need for support" was extracted, so that many examples spoke of the need for support and how and on whom were supported.

"...I wait for the door to be opened but nobody knocks on the door. Everybody left after the funeral, and nobody visited me. I was left with my other children and a husband who was even in worse condition. I asked God what else should have happened to me for my relatives to pay me a visit. I liked someone to come and see us, neighbors did but I expected relatives to pay a visit, they didn't and I let God be the judge ..." (Participant\#7, age 45, mother)

Psychological Impasse: Pain and suffering is a human experience in which parents described the suffering of their child's loss of illness, burning down from the inside and the heart of the knife.

"...Oh God! What can I say, I do not know, I failed in life, my spirit failed, I ate my heart out, this is an endless suffering that is always with me. Have you heard the saying there is no cure for death?" (Participant\#14, age 48, mother)

"...It is good if I know what my problem is, I just know that I am not fine, I don't know what to say, I am just tired of everything, but nothing is wrong with me, I am able to work but I don't know why I don't stand up...” (Participant\#5, age 40, father)

"...How else can someone be lost? Whoever sees me understands that I am dead, it is just a breath inhaled and exhaled..." (Participant\#6, age 48, father)

\section{Frustration}

The majority of participants talked about their own depression and said that their neighbors told them they were depressed or they had such a sensation and spoke of persistent cry, disappointment, hatred of light, and not going to the happy parties of others.

"...It no longer matters what to wear, I don't care at all, my son used to choose my hair color. For example, he told me what color suited me, but he is not here anymore, so I don't care anymore..." (Participant\#17, age 48, mother)

"...In general, I'm more comfortable when I am alone, I like sitting in the room or lie down and just think..." (Participant\#10, age 49, father)

Abandoned: Most of the fathers have been tired of being paternal as they were tired of speaking about their emotions, or because of their husbands, they had to endure this suffering.

"...my child died and left me. It's the people's words that do not leave me alone. Why do you think they come to visit my boy's grave? They came to see my condition. I'm fine, it isn't good that they talk behind my back. since I didn't hit myself in the funeral, they keep saying she wasn't sad. I could see in their eyes that they were laughing at me in their hearts, they say she is like his stepmother rather than his mother because she is so carefree... "(Participant\#7, age 30)

\section{Discussion}

The loss of a child is one of the most painful events and the most devastating tragedy facing parents in their lives. In this study, it was tried to get closer to these families through the establishment of an intimate relationship. The aim was to investigate their problems from their own perspectives. The findings of this study categorized the negative impacts of child loss on parents into seven main concepts, including psychological impasse, need for support, frustration, moving forward, supportive resources, consolidation, abandoned, and dejection. When a child dies, parents experience several changes in their individual and social lives. These parents experience a wide range of psychological-mental, physical, marital, and social problems. According to previous studies, parents experience several changes after losing a child. These changes can be personal (emotions, perspectives, adaptive behaviors, physical, occupational, spiritual beliefs, and sense-oflosing-something) and relational (family members and others). Many of these changes are consistent with the findings of the present study (18-21).

The loss of a child upsets the family balance. Findings of the present study indicate that those families that achieved adaptation to new situations through support and consolation, it strengthened them spiritually and sometimes changed their way of life. This finding is consistent with Glimmers' findings (2012), indicating positive changes in parents' lives (22).

In general, our findings indicate that all participants have experienced personal changes. Similar to previous studies, the majority of family members $(83 \%)$ have experienced some changes after losing a child.

A group of parents, who felt helpless without any support from family or society, moved towards frustration and dejection. Previous studies also show that depression is a periodical phenomenon and recurrent sadness is a common incident $(23,24)$. From the physical aspect, parents are filled with sadness and grief to the extent that leads to physical problems. The health and physical risks are growing among bereaved parents. These physical impacts may appear after the early days of the funeral, when the changes are mainly emotional. They may be secondary to persisting negative emotions or social changes over time $(14,19)$.

\section{Conclusion}

Among the main concepts obtained from participants' experience was moving forward (hope and positive achievements of this experience were its sub-concepts). There are some results from previous studies consistent with our findings, showing that this loss can bring positive effects to families. A study reported that bereaved families have experienced relational changes, mainly in the family. These changes were usually positive (e.g. becoming more intimate and appreciative. However, there are reports about some negative effects too. Therefore, evaluation of positive family outcomes should be taken into consideration in future studies.

It seems that the major step towards the alleviation of existing gaps is providing these families with support from the early days of loss until they get along with the crisis. These findings can be used to provide such families with care and support through the healthcare team, including nurses, doctors, social workers, and clergies, to help them get along with this loss.

Due to the shocking nature of the event of death, and the pain of remembering bitter memories, some families were unwilling to participate. Having an experiment in line with the research by the researcher made it possible to establish a strong relationship between the participants and the researcher. 


\section{Acknowledgment}

The researcher hereby thanks all the families who kindly accepted me and completely cooperated. It is dedicated to the tears shed in describing the pain.

\section{Reference}

1. Boyden JY, Kavanaugh K, Issel LM, Eldeirawi K, Meert KL. Experiences of African American parents following perinatal or pediatric death: A literature review. Death studies. 2014;38(6):374-80.

2. Thompson AL, Miller KS, Barrera M, Davies B, Foster TL, Gilmer MJ, et al. A qualitative study of advice from bereaved parents and siblings. Journal of social work in end-of-life \& palliative care. 2011;7(2-3):153-72.

3. Eggly S, Manning MA, Slatcher RB, Berg RA, Wessel DL, Newth CJ, et al. Language analysis as a window to bereaved parents' emotions during a parent-physician bereavement meeting. Journal of language and social psychology. 2015;34(2):181-99.

4. Hawthorne DM, Youngblut JM, Brooten D. Parent Spirituality, Grief, and Mental Health at 1 and 3Months After Their Infant's/Child's Death in an Intensive Care Unit. Journal of pediatric nursing. 2016;31(1):73-80.

5. Morris AT, Gabert-Quillen C, Friebert S, Carst N, Delahanty DL. The Indirect Effect of Positive Parenting on the Relationship Between Parent and Sibling Bereavement Outcomes After the Death of a Child. Journal of pain and symptom management. 2016;51(1):60-70.

6. ESPINOSA, Javier, EVANS, William N. Maternal bereavement: The heightened mortality of mothers after the death of a child. Economics \& Human Biology, 2013, 11.3: 371-381.

7. Song J, Floyd FJ, Seltzer MM, Greenberg JS, Hong J. Long Term Effects of Child Death on Parents' Health Related Quality of Life: A Dyadic Analysis. Family relations. 2010;59(3):269-82.

8. Price J, Jordan J, Prior L, Parkes J. Living through the death of a child: a qualitative study of bereaved parents' experiences. International journal of nursing studies. 2011;48(11):1384-92.

9. Bruno Michon M. Death of a child: parental perception of grief intensity-end-of-life and bereavement care. 2003.
10. Ronen R, Packman W, Field NP, Davies B, Kramer R, Long JK. The relationship between grief adjustment and continuing bonds for parents who have lost a child. OMEGA-Journal of Death and Dying. 2010;60(1):1-31.

11. Kuhn SK. The process of parental bereavement following the violent death of a child: ProQuest; 2008.

12. Schwab R. Effects of a child's death on the marital relationship: A preliminary study. Death studies. 1992;16 (2):141-54.

13. Wiriya K, Hatthakit U, Wiroonpanich W, Smith-Battle L. Buddhist Mothers' Experience of Suffering and Healing After the Accidental Death of a Child. Pacific Rim International Journal of Nursing Research. 2009;13(3):227 -41 .

14. Murray M. Critical health psychology: Palgrave Macmillan; 2014.

15. McCulloch G, Crook D. The Routledge international encyclopedia of education: Routledge; 2013.

16. Holloway I, Wheeler S. Qualitative research in nursing and healthcare: John Wiley \& Sons; 2013.

17. Polit DF, Beck CT. Nursing research: Generating and assessing evidence for nursing practice: Lippincott Williams \& Wilkins; 2008.

18. Gilbert KR. Couple coping with the death of a child. Death and trauma: The traumatology of grieving. 1997:101-21.

19. Wheeler I. Parental bereavement: The crisis of meaning. Death studies. 2001;25(1):51-66.

20. Davies B, Gudmundsdottir M, Worden B, Orloff S, Sumner L, Brenner P. 'LIVING IN THE DRAGON'S SHADOW” FATHERS'EXPERIENCES OF A CHILD'S LIFE-LIMITING ILLNESS. Death studies. 2004;28(2):111-35.

21. Oliver LE. Effects of a child's death on the marital relationship: A review. Omega-Journal Of Death And Dying. 1999;39(3):197-227.

22. Gilmer MJ, Foster T, Gerhardt C. Changes in Parents After the Death of a Child To Cancer (702). Journal of Pain and Symptom Management. 2012;43(2):419-20.

23. Fish WC. Differences of grief intensity in bereaved parents. Parental loss of a child. 1986:415-28.

24. Martinson I. Grief is an individual journey: Follow-up of families postdeath of a child with cancer. Children and death. 1991:255-65. 